\title{
Variation in Annual Cycle and Mortality in Spotted Souslik in Relation to Population Density in the Northernmost Part of Its Range
}

\author{
A. V. Tchabovsky, A. F. Babitsky, and L. E. Savinetskaya \\ Presented by Academician D.S. Pavlov March 29, 2005
}

Received April 7, 2005

Obligately hibernating mammals, including most of ground-dwelling sciurids, are especially limited in time and energy for successful reproduction. During the short active season between periods of hibernation, they must not only give birth to the offspring and raise the young, but also gain the body weight necessary for surviving through winter and successful reproduction in the next spring $[6,8]$. The time of immergence and winter mortality depend, respectively, on the rate of weight gain and fattening success: ground squirrels may prolong the active period if the weight gain is insufficient, but only up to a certain degree limited by climatic conditions and the state of vegetation. After this time, ground squirrels pass to hibernation if they have not reached the necessary body weight; then, they risk not to survive until spring $[1,2,9]$.

The spotted souslik (Spermophilus suslicus Guld.) is one of the northernmost ground-dwelling sciurids. At the northern border of the species range, in the Moscow oblast, it forms mosaic colonies with a population density as high as 100 animals per hectare or even denser [4]. The short active season (four to five months versus six to seven months in Moldova [3]) and high density, which exacerbates the competition for food and, hence, may negatively affect the rate of weight gain and fattening success, determine especially strict limits for annual cycle variation in these colonies. We expected tat an increase in population density would decrease the rate of weight gain and increase the period of aboveground activity. We also assumed that the fattening success affect the survivability of ground squirrels during hibernation. To test this assumption, we studied the duration of aboveground activity, time of immergence, rate of weight gain, and survival rate of the spotted souslik as related to multiyear population-size variation. We included in analysis only adult males, because the

Severtsov Institute of Ecology and Evolution, Russian Academy of Sciences, Leninskii pr. 33, Moscow, 119071 Russia seasonal activity of females and young animals depended on more factors [8].

The study was performed from April to August (in the period of aboveground activity) in 2001-2003 and in the spring of 2004 on meadows transforming into steppes in the Zaraisk raion of the Moscow oblast. The animals were trapped with wired livetraps [5] in an experimental plot $100 \times 100 \mathrm{~m}$ in size, with sunflower seeds serving as a bait. In the periods of the emergence of adult animals and the appearance of underyearlings on the ground, two-day trapping sessions were performed at least once a week; in other periods, once in ten days. All trapped animals were marked for life by cutting off fingers. We trapped a total of 261 males $(28,84,91$, and 58 in 2001, 2002, 2003, and 2004). On trapping, each male was weighed with an accuracy of $1 \mathrm{~g}$ by means of a Persola spring scales or electronic scales.

The duration of aboveground activity between the emergence and immergence was calculated as the difference between the dates when the first male appeared on the ground and when the last male was trapped. Since the census was not performed daily, we used the "conservative" dates of emergence and immergence calculated, respectively, as the mean between the date of the first trapping and the date of the preceding census and the mean between the date of the last trapping and the date of the next census.

Three weeks beginning from the trapping of the first male in spring were taken to be the post-emergence period. The middle of the two-week period during which more than half males were trapped for the last time was taken to be the beginning of the pre-hibernation period; the date when the last male was trapped on the ground, the end of this period. For the males trapped during the pre-hibernation period, the date of the last trapping was taken to be the date of immergence. the body weights of each male in the post-emergence and pre-hibernation periods were estimated only by the results of the first and the last weighings in the respective period. the rate of weight gain was determined for each male as the difference between the results of the 
The population density, duration of aboveground activity, and fattening of male spotted sousliks in 2001-2003 (Zaraisk raion, Moscow oblast, Russia)

\begin{tabular}{c|c|c|c|c|c|c|c}
\hline Year & $\begin{array}{c}\text { Density, } \\
\text { animals/ha }\end{array}$ & $\begin{array}{c}\text { Date of emer- } \\
\text { gence }\end{array}$ & $\begin{array}{c}\text { Date of im- } \\
\text { mergence }\end{array}$ & $\begin{array}{c}\text { Period of above- } \\
\text { ground activity, } \\
\text { days }\end{array}$ & $\begin{array}{c}\text { Body weight } \\
\text { after emer- } \\
\text { gence, g }(N)\end{array}$ & $\begin{array}{c}\text { Body weight } \\
\text { before immer- } \\
\text { gence, g }(N)\end{array}$ & $\begin{array}{c}\text { Rate of weight } \\
\text { gain, g/day }(N)\end{array}$ \\
\hline 2001 & 36 & 19.04 & 27.06 & 69 & $240 \pm 9.0(19)$ & $380 \pm 11.4(5)$ & $3.0(2)^{* *}$ \\
2002 & 52 & 05.04 & 12.08 & 129 & $241 \pm 7.0(43)$ & $381 \pm 13.8(13)$ & $1.7 \pm 0.12(13)$ \\
2003 & $106^{*}$ & 19.04 & 11.07 & 83 & $233 \pm 5.7(42)$ & $265 \pm 10.3(25)$ & $0.7 \pm 0.11(21)$ \\
\hline
\end{tabular}

* In 2003, the population density was corrected because half the plot was ploughed.

** In 2001, the population size was only two animals; therefore, the error of the mean is not indicated. The pattern of the change in body weight during the season (figure) confirms the high rate of weight gain in 2001.

first and the last weighings in the entire season divided by the number of days between the weighings. The survival rate was estimated as the proportion of males that survived in the experimental plot until the next year among the total number of adult males trapped in the preceding year. The population density (animals per hectare) was measured as the number of adult animals of both sexes trapped in the plot in spring. In 2003, half of the plot was ploughed in spring (for farming purposes); therefore, we corrected the population density, taking into account that only a few animals were trapped in the ploughed half of the plot. All data are presented as the mean \pm error of the mean, if not indicated otherwise.

The population density of sousliks steadily increased from year to year (table). Conversely, the rate of weight gain decreased from year to year (figure), the differences being statistically significant $\left(F_{2,33}=28.8\right.$, $p<0.0001)$ (table). The periods of aboveground activ-

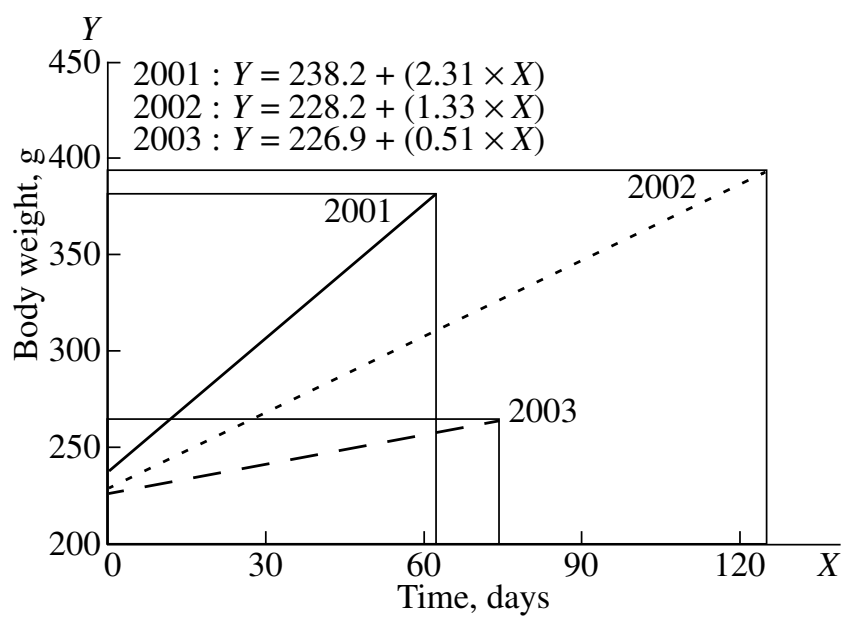

The rate of weight gain and duration of aboveground activity of male spotted sousliks in 2001-2003. Vertical lines show the duration of aboveground activity (the date of emergence it taken to be zero); horizontal lines show the body weight before immergence. Regression equations were calculate for all weighings; therefore, the body weights after emergence and before immergence shown in the figure slightly differ from those shown in the table. ity in 2001 (at a low population density) and 2003 (at a very high density) were considerably shorter than in 2002 (at an intermediate density), when the hibernation was delayed by more than a month, and the immergence dates significantly differed from those observed in both 2001 and 2003 (in both cases, the Mann-Whitney test was $U=0, p<0.0001$ ) (figure; table). In 2001 and 2002, males immerged at the same body weights (the Tukey-HSD test was $p=1.0$ ) (table), namely, $140 \mathrm{~g}$; in 2003 , the body weight by the moment of immergence significantly lower (the Tukey-HSD tests were $p=0.0018$ for 2001 and 2003 and $p=0.0001$ for 2002 and 2003); the increase during the season was only $32 \mathrm{~g}$. The male survival rate decreased from year to year and was significantly lower in 2003 than in 2001 $\left(\chi^{2}=7.45\right.$, d.f. $\left.=1, p=0.006\right)$, although these values in 2001 and 2002 did not differ from each other $\left(\chi^{2}=2.5\right.$, d.f. $=1, p=0.1137)$. The rate of weight gain of surviving males in $2003(0.93 \pm 0.18, N=23)$ significantly differed the rate of weight gain of the males that did not survive until next spring $(0.30 \pm 0.23, N=32, t=-2.0$, d.f. $=53, p<0.05)$. In agreement with the difference in body weight in autumn, males weighed significantly less in the spring of $2004(209 \pm 6.0 \mathrm{~g}, N=37)$ than in 2002 (the Tukey-HSD test, $p=0.03$ ) (table), and differences from these values in 2001 and 2003 approached the level of significance (the Tukey-HSD test, $p=0.09$ and 0.06 , respectively).

The results obtained agree with our hypothesis on a feedback between the population density and the rate of weight gain in ground squirrels. The rate of weight gain changed in inverse proportion to the density, which may have been related to the intensity of competition and the adequacy of food resources [1]. However, the assumption on the negative association between the rate of weight gain and the period of aboveground activity as a mechanism controlling the weight gain necessary for successful wintering confirmed only partly. As expected, the rate of weight gain was lower and the duration of the aboveground activity of males was higher in the year with a high population density (2002) than in the year with a moderate density (2001). The immergence was delayed, which allowed the animals to gain the body weight necessary for successful winter- 
ing, thus ensuring about the same survival rate as in the year with a low density, when the rate of weight gain was higher and the period of aboveground activity, shorter. Unexpectedly, however, this regulatory mechanism determining the feedback between the duration of aboveground activity and the rate of weight gain that has been reported for other ground-dwelling sciurids [6] was ineffective in the year with a very high population density (2003). Gaining daily a negligibly small weight, sousliks immerged early in that year (earlier than in 2002, at a lower density) and, apparently, had not gained enough weight by the time of hibernation. This suggests that the decision on immergence is determined not only by the state of the animal at the given moment, but also by the time left for gaining the necessary body weight. Apparently, a similar mechanism determines the decision on migration in young Belding's ground squirrels [11].

The lack of fat by the moment of immergence in ground squirrels is associated with a high risk of death during hibernation $[10,12]$ or, if the animals survive, a poor state in next spring and, hence, a decrease in reproductive success [7]. Thus, it is conceivable tat the high male mortality rate in winter and poorer state of the males that survived until the spring of 2004 were caused by a too early immergence and an insufficient body weight in the preceding year.

It is obvious that, given the excessively high population density, the extremely low rate of weight gain would not have ensured the necessary fattening success even if the period of aboveground activity had been increased by four to five months (it would have taken the males about 200 days to gain the necessary body weight) (figure). Such a prolongation of the aboveground activity is impossible for a hibernating species whose entire active period at the northern border of the species range is as short as four months [4]. Thus, we found two modes of the regulation of immergence time in the spotted souslik, depending on population density. In the underthreshold mode, a decrease in the rate of weight gain at an increased population density is compensated for by a longer season of activity and has no effect on the survival through winter. In the abovethreshold mode, at an excessively high density and negligibly low rate of weight gain, the animals immerge early and with an inadequately low body weight, which increases the mortality in winter but may decrease the risks related to a "pointless" stay on the ground. In contrast to the normal functioning of the population, this mechanism mediates the density-dependent regulation of population size.

\section{ACKNOWLEDGMENTS}

We are grateful to our colleagues who helped us with the study: O.N. Shekarova, I.A. Volodin, E.A. Volodina, V.A. Kuznetsov, and V. Matrosova. We thank S.A. Shilova, who rendered us various support and assistance with the study and preparation of the manuscript, and K.A. Rogovin, whose advice and comments were of considerable help at the stages of the treatment of the results and the preparation of the article.

This study was supported by the Russian Foundation for Basic Research (project nos. 04-04-48 479 and 05-04-48 575).

\section{REFERENCES}

1. Abaturov, B.D. and Magomedov, M.-R. D., Zool. Zh., 1982, vol. 61, issue 6, pp. 890-900.

2. Lobkov, V.A., Krapchatyi suslik Severo-Zapadnogo Prichernomor'ya: Biologiya, funktsionirovanie populyatsii (Spotted Sousliks of the Northeastern Black Sea Region: Biology and Population Functioning (Odessa: Astroprint), 1999.

3. Lozan, M.N., in Gryzuny Moldavii: Istoriya stanovleniya fauny $i$ ekologii retsentnykh vidov (Rodents of Moldova: The History of the Formation of the Fauna and the Ecology of Recent Species), Chisinau, 1970, vol. 1, pp. 1-168.

4. Shekarova, O.N., Krasnova, E.D., Shcherbakov, A.V., et al., Byull. Mosk. O-va Ispyt. Prir., Otd. Biol., 2003, vol. 108, issue 2, pp. 9-16.

5. Shchipanov, N.A., Zool. Zh., 1987, vol. 66, issue 5, pp. 759-761.

6. Buck, C.L. and Barnes, B.M., J. Mammal., 1999, vol. 80, pp. 430-442.

7. Dobson, F.S., Am. Natur., 1992, vol. 140, no. 1, pp. 109125.

8. Millesi, E., Huber, S., Everts, L.G., et al., Ethnology, 1999, vol. 105, pp. 163-175.

9. Morton, M.L., Maxwell, C.S., and Wade, C.E., Great Basin Natur., 1974, vol. 34, pp. 121-134.

10. Neuhaus, P., Behav. Ecol. Sociobiol., 2000, vol. 48, pp. $75-83$.

11. Nunes, S., Ha, C.T., Garrett, P.J., et al., Anim. Behav., 1998, vol. 55, pp. 605-614.

12. Slade, N.A. and Balph, D.F., Ecology, 1974, vol. 55, no. 5 , pp. $989-1003$. 